\title{
Comparison of macular thickness by optical coherence tomography measurements after uneventful phacoemulsification using ketorolac tromethamine, nepafenac, vs a control group, preoperatively and postoperatively
}

This article was published in the following Dove Press journal:

Clinical Ophthalmology

\section{Ricardo Alexandre Stock Daiane Karen Galvan Rafael Godoy Elcio Luiz Bonamigo}

Universidade do Oeste de Santa Catarina, Joaçaba, Santa Catarina, Brazil
Correspondence: Ricardo Alexandre Stock

Centro Oftalmológico Belotto Stock, Avenida Barão do Rio Branco, 589, Joaçaba, Santa Catarina 89600-000, Brazil Tel/fax +55 4935220788

Email ricardostockreal@gmail.com
Purpose: To analyze, using optical coherence tomography, the macular thickness values of patient groups using nonsteroidal anti-inflammatory drug (NSAID) eye drops or artificial tears during uncomplicated cataract surgery.

Methods: A total of 77 eyes from 42 patients were analyzed. The patients were divided into three groups, each using one of the following ophthalmic sterile suspensions: nepafenac (21 eyes), propylene glycol (24 eyes), or ketorolac tromethamine (32 eyes).

Results: The mean macular thicknesses of the nepafenac group, preoperatively as well as at 1 , 7 , and 45 days postoperatively, were $216.42,216.61,222.47$, and 218.28 , respectively; those of the propylene glycol control group were $218.29,214.50,219.37$, and 228.45, respectively; and those of the ketorolac tromethamine group were 217.46, 220.71, 225.25, and 228.46, respectively. There were no significant differences between groups at any time, with $p$-values of $0.971,0.6742,0.6711$, and 0.327 , respectively.

Conclusion: During the study period, no significant differences in macular thickness were observed between the patient groups using two types of NSAIDs or between those groups and the control group that used propylene glycol, indicating that neither drug was superior to the other or the placebo. However, a slight macular thickening, without reduction of visual acuity, was observed in all groups.

Keywords: macular edema, nepafenac, ketorolac tromethamine, OCT, cataract surgery, macular thickness, prevention

\section{Introduction}

Cataracts remain the leading cause of blindness in the world, and cataract surgery is one of the most frequently performed surgical procedures. Cystoid macular edema $(\mathrm{CME})$ is the most common cause of visual impairment related to the postoperative period of uncomplicated cataract surgery. CME has a low incidence of $0.1 \%-2.35 \%{ }^{1}$ occurs between the fourth and tenth postoperative week; and can manifest as visual blurring, image distortion, photophobia, or some combination therein. ${ }^{2,3}$ There are two types of CME: one is a subclinical type, in which macular thickening is observed normally on optical coherence tomography (OCT) and with no reduction of visual acuity; the other type is associated with the reduction of visual acuity. 
Ocular surgery causes inflammatory events with the production of prostaglandins, leading to the accumulation of intraretinal fluid and macular thickening. ${ }^{4}$ Mechanical traction on perifoveal retinal capillaries during phacoemulsification may contribute to macular thickening and even CME. ${ }^{5}$ Inflammatory mediators, when diffused to the vitreous and retina, cause vasodilatation and disruption of the bloodretinal barrier, and the fluid accumulation in the retina can develop CME. ${ }^{6}$

The incidence of CME with clinically significant vision loss after phacoemulsification surgery is only $0.2 \%-1.4 \%{ }^{7,8}$ However, the frequency of CME depends on the diagnostic method used. When using more sensitive instruments, such as OCT, the estimated rate is $4 \%-40 \%$. In most cases, CME regresses spontaneously after $3-12$ months, and only $1 \%$ of patients experience the loss of visual acuity. ${ }^{9}$

Based on controversial data in the literature about the use of NSAIDs in preventing CME, the objective of this study was to use OCT to analyze the macular thickness of three groups of patients using nonsteroidal anti-inflammatory drugs (NSAIDs) or an eye lubricant during the pre- and postoperative periods of cataract surgery.

\section{Methods}

This double-blind, randomized, comparative, quantitative, prospective study was performed on three groups of patients using one of the following sterile ophthalmic suspensions both before and after cataract surgery: $0.3 \%$ nepafenac $\left(\mathrm{Nevanac}^{\circledR}\right.$ $\mathrm{UNO}$ ), $0.5 \%$ ketorolac tromethamine (Acular ${ }^{\circledR} \mathrm{LS}$ ), or propylene glycol (Systane ${ }^{\circledR} \mathrm{UL}$ ), the last of which was used as a control. The eye drops were used preoperatively ( 2 days and 5 minutes before surgery) and postoperatively for 45 days. Nepafenac was applied once per day, ketorolac tromethamine was applied three times per day, and propylene glycol was also used three times per day. Data were collected between 10 November 2014 and 15 January 2016.

All patients were submitted to a $1.8-\mathrm{mm}$ clear corneal incision phacoemulsification by the same experienced surgeon. A foldable intraocular lens implantation in the bag was performed in all patients.

We included all patients who had an uneventful phacoemulsification and who completed the minimal follow-up period of 45 days in the study. Patients who had complicated phacoemulsification were excluded, as were patients with a medical history of previous ocular surgery and patients with glaucoma and uveitis. Those patients who were carriers of certain systemic diseases (including diabetes mellitus) were also excluded. Patients with retinal disease, those whose OCT was not well performed (uncooperative patients or those with cataracts that did not allow the test to be performed with quality), and those with scores of $<6$ were also excluded. All patients were submitted to a complete ophthalmological evaluation, including visual acuity test, slit lamp examination, ocular tonometry, and fundus examination.

OCT was performed using a Stratus III device both preoperatively before cataract surgery and on the 1 st, 7 th, and 45th postoperative days. A macular thickness map was used for the image acquisition, and retinal thickness/volume was recorded after image capture to analyze the macular retinal thickness. An ophthalmologist experienced in fovea-centered image acquisition performed all of the tests.

The sample was composed of 77 eyes from 42 patients; 35 patients had a bilateral surgery with a 1-week interval between the eyes, and seven patients had only one eye surgery. A total of 32 eyes were included in the ketorolac tromethamine group, 21 were included in the nepafenac group, and 24 were included in the control group that used propylene glycol. The patients were randomly assigned to the use of a medication using an Excel spreadsheet created for that purpose. Participants were included when diagnosed as having cataract, undergoing surgery, and willing to complete the minimum data collection follow-up period. A signed free and informed consent document was obtained from all patients. The research followed the guidelines of the Declaration of Helsinki and was approved by the Research Ethics Committee of the University of the West of Santa Catarina under the number 826.475. The results were submitted to analysis of variance using the Tukey test at $5 \%$ probability.

\section{Results}

The mean macular thicknesses of the group that used nepafenac drops preoperatively and at 1,7 , and 45 days postoperatively were $216.42,216.61,222.47$, and 218.28 , respectively; these values for the control group that used propylene glycol were 218.29, 214.50, 219.37, and 228.45, respectively; and those for the group that used ketorolac tromethamine were 217.46, 220.71, 225.25, and 228.46, respectively. The mean, $\mathrm{SD}$, and $p$-values are shown in Table 1.

The mean macular thickness results of the three groups using eye drops, measured in microns, are shown in Figure 1.

\section{Discussion}

CME remains a common cause of visual impairment in cataract surgery, ${ }^{10}$ and OCT has revolutionized the analysis 
Table I Macular thickness mean and SD during the pre- and postoperative periods

\begin{tabular}{|c|c|c|c|c|c|c|c|}
\hline \multirow[t]{2}{*}{ Day } & \multicolumn{2}{|c|}{$\begin{array}{l}\text { Nepafenac (Nevanac } \\
\text { UNO) }\end{array}$} & \multicolumn{2}{|c|}{$\begin{array}{l}\text { Propylene glycol } \\
\text { (control group) }\end{array}$} & \multicolumn{2}{|c|}{$\begin{array}{l}\text { Ketorolac } \\
\text { tromethamine } \\
\left(\text { Acular }^{\circledR} \text { LS) }\right. \\
\end{array}$} & \multirow[t]{2}{*}{$p$-value } \\
\hline & Mean & SD & Mean & SD & Mean & SD & \\
\hline Preoperative & 216.42 & 23.35 & 218.29 & 26.25 & 217.46 & 26.79 & 0.971 \\
\hline Day I & 216.61 & 23.12 & 214.5 & 28 & 220.71 & 27.66 & 0.674 \\
\hline Day 7 & 222.47 & 23.27 & 219.37 & 28.26 & 225.25 & 21.66 & 0.671 \\
\hline Day 45 & 218.28 & 19.15 & 228.45 & 29.63 & 228.46 & 27.85 & 0.327 \\
\hline
\end{tabular}

of diseases that affect the retina and their management. ${ }^{11}$ Most clinical trials have analyzed OCT measurements of macular thickness, including studies of CME after cataract surgery. ${ }^{12}$

In the current study, no significant difference was found in the macular thickness at postoperative days 1,7 , and 45 after uncomplicated cataract surgery among the ketorolac tromethamine, nepafenac, and propylene glycol groups. This result corroborates that of Tzelikis et al, ${ }^{13}$ who showed that the prophylactic use of NSAIDs after uncomplicated cataract surgery was unable to prevent macular edema compared with placebo. The present study showed that nepafenac drops were associated with the lowest standard deviation of the three groups; thus, these eyes showed less longitudinal variation in macular thickness during the study period, except on the 45th day, but with no significant difference at any measurement (days 1, 7, and 45 postoperatively).

Similarly, a randomized study of 162 patients, where 54 patients composed the placebo group, 54 composed the
$0.5 \%$ ketorolac group, and 54 composed $0.1 \%$ nepafenac group, did not find a significant difference among the three groups in terms of macular thickness. In that study, all of the patients used the medication topically, starting on the day of phacoemulsification (preoperatively) and continuing with its use for 4 weeks. ${ }^{14}$

However, a previous study ${ }^{15}$ of prophylactic use suggested that nepafenac is a highly promising drug for preventing $\mathrm{CME}$ after cataract surgery, and another study ${ }^{16}$ that examined the use of $0.5 \%$ ketorolac tromethamine found that it effectively decreased postoperative macular edema. A third study performed using fluorescein angiography compared a group of 30 patients using nepafenac with 29 patients using fluorometholone and found that the incidence of CME was significantly lower in the first group $(p<0.0001)$ during both the second ( $p=0.0266)$ and fifth $(p=0.0055)$ weeks. ${ }^{17}$ A meta-analysis concluded that nepafenac and ketorolac are equally effective in controlling post-cataract surgery ocular inflammation, but nepafenac was more effective in reducing conjunctival hyperemia and ocular discomfort. ${ }^{18}$ However,

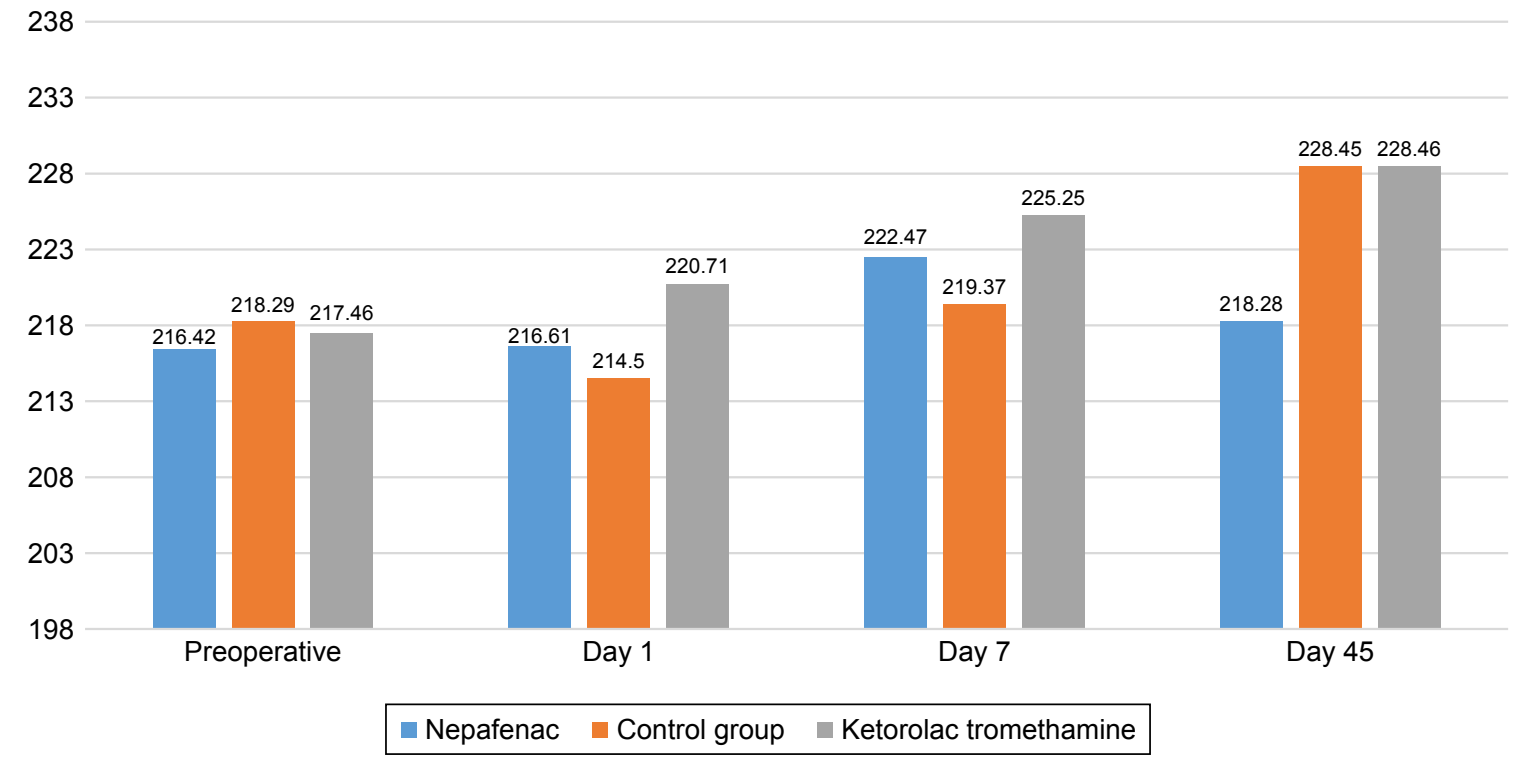

Figure I Mean macular thickness by group. 
another study found that although CME is common after cataract surgery, nepafenac shows no benefit in the absence of risk factors. ${ }^{19}$

One reviewed article found that even when adopting evaluation methods that are theoretically more sensitive than visual acuity measurement (eg, contrast sensitivity), significant differences do not occur in the prophylactic treatment of CME. A smaller increase in macular thickness and less loss of contrast sensitivity might exist, thereby justifying the use of NSAIDs for high-risk patients. ${ }^{20}$ However, a recent study concluded that the risk of CME in patients who underwent cataract surgery was low and that the reduction with the use of anti-inflammatory drugs was modest. $^{21}$

One study that compared bromfenac with nepafenac concluded that the former was superior and provided less macular thickening and better visual acuity than the latter, which suggests that other drugs might be more efficient with regard to macular edema prevention. ${ }^{22}$ A recent study found that bromfenac is safe and effective for preventing or treating CME. ${ }^{4}$ Another study analyzed the use of nepafenac with topical prednisone and concluded that this combination was more effective than prednisone alone in preventing CME after phacoemulsification. This finding alerts us to the potential effectiveness of combination therapies and the need for additional studies to evaluate this possibility. ${ }^{23}$

Another aspect to be considered is that the lack of patient adherence in administering eye drops may decrease the effect of nonhormonal therapy, though the administration of ketorolac in the anterior chamber did not maintain good concentrations following cataract surgery. ${ }^{24}$

\section{Conclusion}

Based on the results obtained from the OCT measurement, no significant differences were found in macular thickness variation among the groups of patients who used prophylactic eye drops of nepafenac, ketorolac tromethamine, or propylene glycol after uncomplicated phacoemulsification.

Although the NSAIDs were well tolerated by all patients of both relevant groups, our study failed to establish whether they affected the development of macular thickening once there were no significant differences between groups in all measurements. During the study period, none of the patients presented with CME.

Finally, we recognized that our sample is too small; further study with a large sample is needed. The possibility of bias regarding the 1-week interval between the eyes on the analysis of macular thickening in the second eye is also highlighted here.

\section{Disclosure}

The authors report no conflicts of interest in this work.

\section{References}

1. Yilmaz T, Cordero-Coma M, Gallagher MJ. Ketorolac therapy for the prevention of acute pseudophakic cystoid macular edema: a systematic review. Eye. 2012;26(2):252-258.

2. Bowling B. Kanski: Oftalmologia Clínica: uma abordagem sistemática [Kanski: Clinical Ophthalmology: A Systematic Approach]. 8th ed. Rio de Janeiro: Elsevier; 2016. Portuguese.

3. Yonekawa Y, Eliott D, Kim I, Feldman BH, Shah VA, Yonekawa Y. Pseudophakic cystoid macular edema (Irvine-Gass syndrome). Eyewiki. American Academy of Ophthalmology; 2014. Available from: http:// eyewiki.aao.org/Pseudophakic_Cystoid_Macular_Edema_(IrvineGass_Syndrome). Accessed January 15, 2017.

4. Guo S, Patel S, Baumrind B, et al. Management of pseudophakic cystoid macular edema. Surv Ophthalmol. 2015;60(2):123-137.

5. Sheppard JD. Topical bromfenac for prevention and treatment of cystoid macular edema following cataract surgery: a review. Clin Ophthalmol. 2016;10:2099-2111.

6. Yüksel B, Karti Ö, Kusbeci T. Topical nepafenac for prevention of postcataract surgery macular edema in diabetic patients: patient selection and perspectives. Clin Ophthalmol. 2017;11:2183-2190.

7. Bélair ML, Kim SJ, Thorne JE, et al. Incidence of cystoid macular edema after cataract surgery in patients with and without uveitis using optical coherence tomography. Am J Ophthalmol. 2009;148(1):128-135.

8. Shelsta HN, Jampol LM. Pharmacologic therapy of pseudophakic cystoid macular edema: 2010 update. Retina. 2011;31(1):4-12.

9. Bonomo PP, Aggio FB, Jiun HS, Farah ME. Edema macular cistoide pós-facectomia [Post-facectomy cystoid macular edema]. In: Farah ME, editor. OCT: Tomografia de Coerência Óptica Texto e Atlas. 2nd ed. Rio de Janeiro: Guanabara Koogan; 2010:179-184. Portuguese.

10. Nelson ML, Martinin A. Managing cystoid macular edema after cataract surgery. Curr Opin Ophthalmol. 2003;14(1):39-43.

11. Puliafito CA, Hee MR, Lin CP, et al. Imaging of macular diseases with optical coherence tomography. Ophthalmology. 1995;102(2):217-229.

12. Srinivasan VJ, Wojtkowski M, Witkin AJ, et al. High-definition and 3-dimentional imaging of macular pathologies with high-speed ultrahigh-resolution optical coherence tomography. Ophthalmology. 2006; 113(11):2054-2065.

13. Tzelikis PF, Vieira M, Hida WT, et al. Comparison of ketorolac $0.4 \%$ and nepafenac $0.1 \%$ for the prevention of cystoid macular oedema after phacoemulsification: prospective placebo-controlled randomised study. Br J Ophthalmol. 2015;99(5):654-658.

14. Almeida DR, Khan Z, Xing L, et al. Prophylactic nepafenac and ketorolac versus placebo in preventing postoperative macular edema after uneventful phacoemulsification. J Cataract Refract Surg. 2012;38(9): $1537-1543$

15. Hariprasad SM, Akduman L, Clever JA, Ober M, Recchia FM, Mieler WF. Treatment of cystoid macular edema with the new-generation NSAID nepafenac 0.1\%. Clin Ophthalmol. 2009;3:147-154.

16. Almeida DR, Johnson D, Hollands H, et al. Effect of prophylactic nonsteroidal antiinflammatory drugs on cystoid macular edema assessed using optical coherence tomography quantification of total macular volume after cataract surgery. J Cataract Refract Surg. 2007;34(1): 64-69.

17. Miyake K, Ota I, Miyake G, Numaga J. Nepafenac $0.1 \%$ versus fluorometholone $0.1 \%$ for preventing cystoid macular edema after cataract surgery. J Cataract Refract Surg. 2011;37(9):1581-1588.

18. Zhao X, Xia S, Wang E, Chen Y. Comparison of the efficacy and patients' tolerability of Nepafenac and Ketorolac in the treatment of ocular inflammation following cataract surgery: a meta-analysis of randomized controlled trials. PLoS One. 2017;12(3):e0173254.

19. McCafferty S, Harris A, Kew C, et al. Pseudophakic cystoid macular edema prevention and risk factors; prospective study with adjunctive once daily topical nepafenac $0.3 \%$ versus placebo. BMC Ophthalmol. 2017; 17(1):16. 
20. Carricondo PC, Abalem MF, Machado CG, Kara-Junior N. Prophylaxis and treatment of cystoid macular edema after cataract surgery. Rev Bras Oftalmol. 2015;74(2):113-118.

21. Bobeck S, Modjtahedi JF, Paschal MB, Tiffany QL, Donald SF. Antiinflammatory drugs for macular edema prophylaxis following cataract surgery. Am J Ophthalmol. 2017;176:174-182.

22. Cable M. Comparison of bromfenac $0.09 \%$ QD to nepafenac $0.1 \%$ TID after cataract surgery: pilot evaluation of visual acuity, macular volume, and retinal thickness at a single site. Clin Ophthalmol. 2012; 6(1):997-1004.
23. Wolf EJ, Braunstein A, Shih C, Braunstein RE. Incidence of visually significant pseudophakic macular edema after uneventful phacoemulsification in patients treated with nepafenac. J Cataract Refract Surg. 2007;33(9):1546-1549.

24. Katsev DA, Katsev CC, Pinnow J, Lockhart CM. Intracameral ketorolac concentration at the beginning and end of cataract surgery following preoperative topical ketorolac administration. Clin Ophthalmol. 2017; 11:1897-1901.

\section{Publish your work in this journal}

Clinical Ophthalmology is an international, peer-reviewed journal covering all subspecialties within ophthalmology. Key topics include: Optometry; Visual science; Pharmacology and drug therapy in eye diseases; Basic Sciences; Primary and Secondary eye care; Patien Safety and Quality of Care Improvements. This journal is indexed on

Submit your manuscript here: http://www.dovepress.com/clinical-ophthalmology-journal

\section{Dovepress}

PubMed Central and CAS, and is the official journal of The Society of Clinical Ophthalmology (SCO). The manuscript management system is completely online and includes a very quick and fair peer-review system, which is all easy to use. Visit http://www.dovepress.com/ testimonials.php to read real quotes from published authors. 